\title{
Dentinal Tubule Disinfection with Propolis \& Two Extracts of Azadirachta indica Against Candida albicans Biofilm Formed on Tooth Substrate
}

\author{
Dakshita Joy Sinha ${ }^{1}$, Paridhi Garg ${ }^{1, *}$, Anurag Verma ${ }^{2}$, Vibha Malik $^{3}$, Edgar Richard Maccune ${ }^{3}$ \\ and Agrima Vasudeva ${ }^{1}$ \\ ${ }^{1}$ Conservative Dentistry \& Endodontics, Kothiwal Dental College \& Research Centre, Moradabad (U.P.)- 244001, India \\ ${ }^{2}$ School of Pharmaceutical Sciences, IFTM University, Moradabad, India, ${ }^{3}$ Dr. Vibha Pathlabs, Moradabad, India
}

\begin{abstract}
Aim: This study evaluates the disinfection of dentinal tubules using Propolis, Azadirachta indica (alcoholic and aqueous extracts), 2\% chlorhexidine gel and calcium hydroxide against Candida albicans biofilm formed on tooth substrate. Materials \& Method: One hundred and five human teeth were infected with Candida albicans for 2 days. Samples were divided into 7 groups. Group I- Propolis, Group II- Alcoholic extract of Azadirachta indica, Group III- Aqueous extract of Azadirachta indica, Group IV- 2\% Chlorhexidine, Group V- Calcium hydroxide, Group VI- Ethanol and Group VII- Saline (negative control). At the end of 1,3 and 5 days, the antimicrobial efficacy of medicaments against Candida albicans was assessed at the depths of $200 \mu \mathrm{m}$ and $400 \mu \mathrm{m}$. Results: The overall percentage inhibition of fungal growth (at $200 \mu \mathrm{m}$ and $400 \mu \mathrm{m}$ depth) was $99.2 \%$ with $2 \%$ chlorhexidine gel. There was no statistical difference between propolis, alcoholic extract of Azadirachta indica (neem) and 2\% chlorhexidine. Conclusion: Propolis and alcoholic extract of Azadirachta indica performed equally well as that of $2 \%$ Chlorhexidine.
\end{abstract}

Keywords: Azadirachta indica, calcium hydroxide, Candida albicans, chlorhexidine, dentinal tubule disinfection, propolis.

\section{INTRODUCTION}

Dentinal tubules are exposed to microbial invasion when a breach in the integrity of the overlying enamel or cementum occurs, following a cariogenic or a periodontal insult. If this invasion cannot be overcome by the host defences, it results in pulpal necrosis, infection of the root canal system and periapical disease [1]. One of the important objectives of root canal treatment is the elimination of the microorganisms from the root canal system [2]. Several hundred microbial species are known to inhabit the oral cavity but relatively small and selected group of microbes is involved in the invasion of dentinal tubules and subsequent infection of the root canal space. Gram-positive organisms dominate the tubule microflora in both carious and non-carious dentin. It is difficult to deliver intracanal medicaments in the depth of dentinal tubules, leading to survival of the microbes. If opportunistic conditions occur, they may become a focal source of reinfection [3].

Fungi are chemoorganotroph eukaryotic microorganisms that may be found in 2 basic forms: molds and yeasts. Candida species have surface molecules that mediate adherence to host tissues. Candida species are also able to bind to collagen types I and IV. C.albicans produces hydrolytic enzymes that may be involved in the damage to the periradicular tissues [4]. Enzymes include secreted aspartyl proteinase, collagenase, aminopeptidases, glucosaminidases, acid and

\footnotetext{
*Address correspondence to this author at the Department of Conservative Dentistry \& Endodontics, Kothiwal Dental College \& Research Centre, Moradabad (U.P.)- 244001, India; Tel: 9997052495;

E-mail: paridhigarg03@gmail.com
}

alkaline phosphatases, hyaluronidase, and chondroitin sulfatase, all of which have some effect in the degradation of extracellular matrix proteins [5]. It has been shown that a collagenolytic enzyme produced by this fungal species may degrade the human dentin collagen [6]. C. albicans is often described as a dimorphic fungus that exists in blastospore and hyphal forms. It has been consistently suggested that the transition from the blastospore to the hyphal form represents a change from a commensal to a pathogenic state $[7,8]$. but it has not been found to be true [9]. The properties of a growing hypha may confer the ability to invade host tissues and escape phagocytosis by macrophages [7]. However, although transformation from yeast to hyphal form may be important, it is not always a prerequisite for infection to occur [10]. Indeed, most infections caused by C.albicans are populated by both yeast and filamentous morphologic forms, suggesting that both have a role in the development and progression of the disease [11].

Two percent chlorhexidine is one of the most versatile irrigants and an intracanal medicaments in vital and non-vital teeth. Its efficacy is based on the interaction between the positive charge of the molecule and the negatively charged phosphate groups on the microbial cell wall, which allows the CHX molecule to penetrate into the microbes with toxic effects [12]. It also retains its antimicrobial activity in the presence of blood and other organic matter [13].

Propolis is a brownish resinous substance collected mainly from plants, by the bees. It is a potent antibacterial, antiviral, antifungal and antiprotozoan activities [14]. The main chemical elements present in propolis are flavonoids, phenolics, and various aromatic compounds [15]. 
Azadirachta indica (Neem) is a tree with medicinal value. Each part of the tree has been explored in phytotherapy. The leaves contain alkaloids, glycosides, saponins, flavonoids, steroids, anthraquinone and tannic acid, which are of medicinal value [16].

$\mathrm{Ca}(\mathrm{OH})_{2}$ is believed to have many of the properties of an ideal root canal dressing, mainly due to its alkaline $\mathrm{pH}[17$, 18]. It is microbicidal [19] and neutralizes the remaining tissue debris in the root canal system. [20] $\mathrm{Ca}(\mathrm{OH})_{2}$ also promotes an alkalinizing osteogenic environment on the surrounding tissues through the continuous release of $\mathrm{OH}$ - ions. $[17,21]$ Furthermore, $\mathrm{Ca}(\mathrm{OH})_{2}$ mediates the neutralization of lipopolysaccharides [22] and thus helps in cleansing the root canal [20].

The aim of this study is to evaluate the dentinal tubule disinfection with Propolis, Alcoholic \& aqueous extract of Azadirachta indica, 2\% Chlorhexidine and calcium hydroxide against Candida albicans biofim formed on tooth substrate. There has been no study evaluating the dentinal tubule disinfection with Azadirachta indica till date.

\section{MATERIALS \& METHOD}

\section{Preparation of Dentine Specimens}

The model proposed by Haapasalo \& Ørstavik (1987) [23] was modified. One hundred and five single-rooted human mandibular premolar teeth freshly extracted for orthodontic reasons were selected for the study.

A rotary diamond disc was used to decoronate the teeth below the cementoenamel junction and the apical part of the root to obtain $6 \mathrm{~mm}$ of the middle third of the root (Fig. 1). Cementum was removed from the root surface. Gates Glidden drills no. 3 in a slow-speed handpiece was used to standardize the internal diameter of the root canals. The specimens were placed in an ultrasonic bath of $17 \%$ ethylenediaminetetraacetic acid for $5 \mathrm{~min}$ followed by $3 \% \mathrm{NaOCl}$ for 5 $\mathrm{min}$ to remove organic and inorganic debris. The traces of chemicals used were removed by immersing the dentine specimens in an ultrasonic bath containing distilled water for $5 \mathrm{~min}$. All the specimens were then sterilized in an autoclave for two cycles. The first cycle at $121^{\circ} \mathrm{C}$ and the second with the specimens immersed in $1 \mathrm{~mL}$ of tryptone soya (TS) broth in individual microcentrifuge tubes [24].

\section{Contamination of the Specimens}

C. albicans ATCC 10231 (Himedia, Mumbai L. No. 443207) was grown in saboraud dextrose agar (SDA) (Himedia, Mumbai) for 24h (Fig. 2). The culture was suspended in $5 \mathrm{~mL}$ of SDA broth and incubated for $4 \mathrm{~h}$ at $37^{\circ} \mathrm{C}$ and its turbidity adjusted to 0.5 McFarland standard with sterile SDA broth [25]. Each dentine block was placed in pre-sterilized microcentrifuge tubes containing $1 \mathrm{~mL}$ of the TS broth. $50 \mu \mathrm{L}$ of the inoculums containing the $C$. albicans was transferred into each of the microcentrifuge tubes. At the end of $24 \mathrm{~h}$, the dentine specimens were transferred into fresh broth containing $C$. albicans. All procedures were carried out under laminar flow. Purity of the culture was checked by subculturing $5 \mu \mathrm{L}$ of the broth from the incubated dentine specimens in SDA broth on SDA plates [26]. Contamination of the dentine specimens were carried out for a period of 2 days.

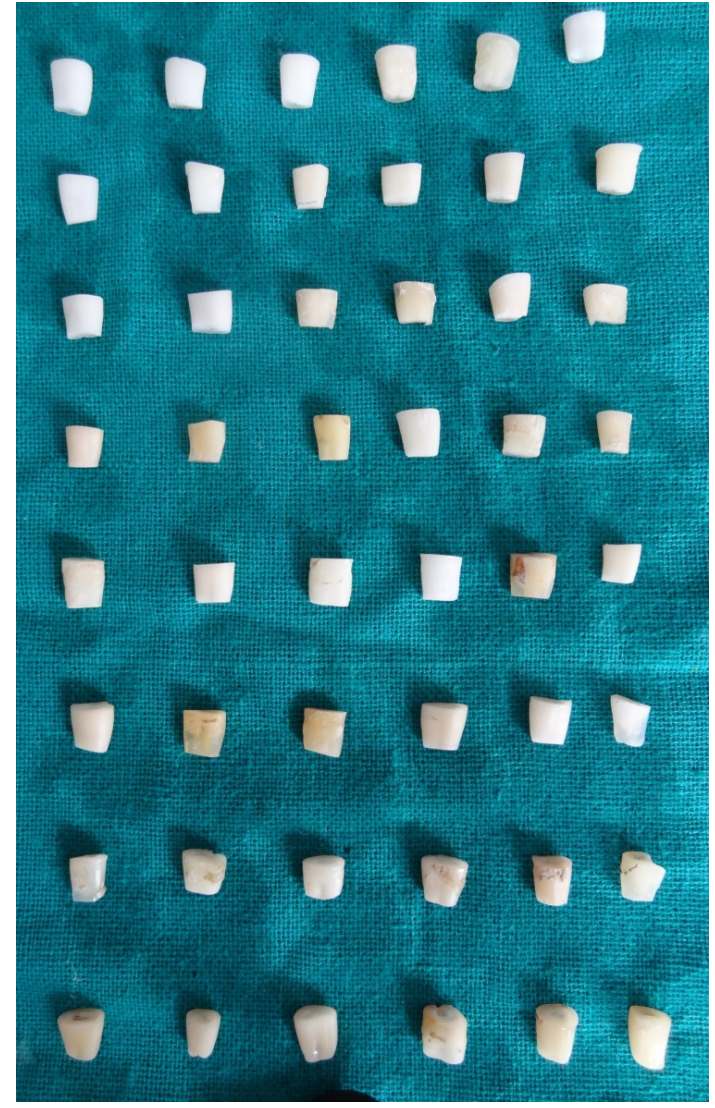

Fig. (1). Prepared specimens.

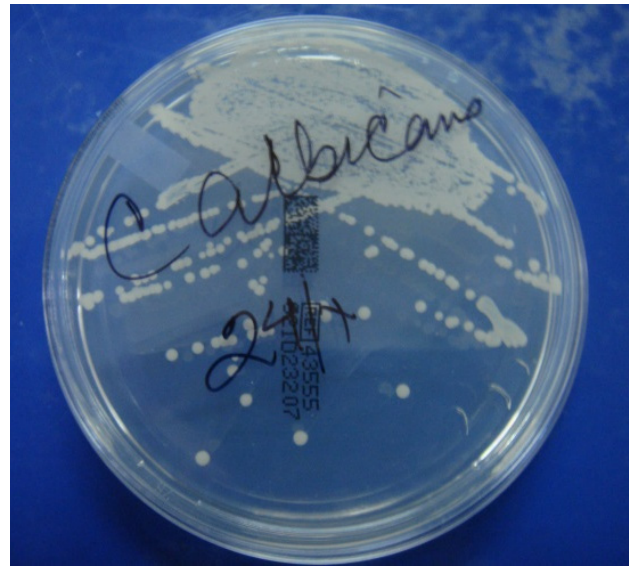

Fig. (2). Candida albicans cultured on Sabouraud dextrose Agar.

\section{Antimicrobial Assessment}

At the end of 2 days, the specimens were irrigated with 5 $\mathrm{mL}$ of sterile saline to remove the incubation broth. Then, the specimens were assigned into 7 groups $(\mathrm{n}=15$ dentine blocks each).

Group 1- Propolis (Herbal Biosolutions, Delhi) was prepared by diluting a $33 \%$ commercially available alcoholic extract using warm saline in a ratio $2: 1$, to form an $11 \%$ alcoholic extract [27]. Then, it was made into gel using Hydroxypropyl methylcellulose (Himedia).

Group 2- Alcoholic extract of Azadirachta indica was prepared using $25 \mathrm{~g}$ of fresh neem leaves powder of $99 \%$ 
purity (The Indian Neem Tree Company, Mumbai) was added to $50 \mathrm{ml}$ of absolute ethanol (Sterling Chemicals and Alcohols Pvt. Ltd., Mumbai). Mixture was macerated for 1-2 min, then extract was filtered through muslin cloth for coarse residue and then through filter paper for finer residue [28]. It was made into a gel by using HPMC.

Group 3- Aqueous extract of Azadirachta indica (Neem) was prepared by mixing $25 \mathrm{~g}$ of dry powder of neem leaves (The Indian Neem Tree Company, Mumbai) with $100 \mathrm{ml}$ of sterile distilled water in a round bottom flask with occasional shaking. The extracts were then filtered through a muslin cloth for coarse residue and then through a Whatman no. 1 filter paper and kept in an airtight amber-colored container [29] It was made into a gel by using HPMC.

Group 4- $2 \%$ Chlorhexidine diacetate powder (2\% solution was made and then gel was prepared by mixing it with HPMC as a thickening agent and distilled water) [30].

Group 5- Calcium Hydroxide + HPMC (150 mg of calcium hydroxide powder was mixed with $0.15 \mathrm{ml}$ of the vehicle, i.e., distilled water) [31].

Group 6- Absolute Ethanol

\section{Group 7- Sterile Saline (Negative Control)}

Hydoxypropyl methyl cellulose (HPMC) was used as a thickening agent for Groups 1,2,3,4 and 5 to standardize all the test solutions, which is an inert polymer [32].

The medicaments were placed inside the canals and sealed at both ends with paraffin wax. They were then incubated in an aerobic environment for $37^{\circ} \mathrm{C}$. At the end of 1,3 , and 5 days $(n=5$ each), harvesting of dentine was carried out at two depths $(200$ and $400 \mu \mathrm{m})$ with Gates Glidden drills no 4 and 5, respectively [24]. The collected dentine shavings were transferred into $1 \mathrm{~mL}$ of sterile SDA broth and incubated in an aerobic environment at $37^{\circ} \mathrm{C}$ for $24 \mathrm{~h}$. After $24 \mathrm{~h}$, the contents of each tube were serially diluted, $100 \mu \mathrm{L}$ of the broth in $100 \mu \mathrm{L}$ of sterile saline five times. $50 \mu \mathrm{L}$ of the dilution was then plated on SDA plates and incubated for $24 \mathrm{~h}$. Colonies were counted and readings were tabulated. The results were statistically analysed by ANOVA and post hoc tukey test.

\section{RESULTS}

The current study showed that 5 medicaments studied exerted antifungal activity. Contamination of the dentin blocks was confirmed when debris samples harvested from the saline group (negative control) yielded positive growth. Table 1 shows the antifungal activity, measured at 2 depths (200 and $400 \mu \mathrm{m})$ and at 3 time intervals (1, 3, and 5 days).

There was no significant difference between Propolis and Neem (Alc. extract); Propolis and 2\% Chlorhexidine; Neem (Alc.) and 2\% Chlorhexidine and Ethanol and Saline, whereas all the other groups had significant differences. On the basis of above analysis, the following order of antimicrobial efficacy of different medicaments was observed (Fig. 3):

\section{DISCUSSION}

The in vitro model developed by Haapasalo \& Ørstavik (1987) [23] was modified and used to assess the efficacy of endodontic medicaments in the disinfection of dentinal tubules. Human permanent teeth were used instead of the bovine teeth as suggested by Basrani et al. [33], as human dentin blocks would simulate the clinical scenario better. Lynne et al. [34] further modified this model to include quantitative analysis of microbes in the dentinal tubules to define a percentage of reduction in CFU in infected dentine before and after the application of intracanal medicaments. Since apical dentine is mostly sclerotic and physically impedes microbial invasion, mid-root sections were taken. Invasion of coronal and mid-root dentin occurs more readily whereas the extent and depth of invasion are significantly less in apical dentin, because of less patent dentinal tubules [35] The samples were tested at two depths, $200 \mu \mathrm{m}$ and $400 \mu \mathrm{m}$, because calcium hydroxide is known to penetrate only upto 200 to 300 $\mu \mathrm{m}$ [36]. Thus, disinfection can be assessed better at these two depths. Three time periods have been taken to assess the disinfection because the effective antimicrobial action of the tested intracanal medicaments decreased after 48 hours [37], therefore, time periods chosen to evaluate the antimicrobial assessment were first and third day. Panagiotis et al. [38] have shown that a 5-day period is adequate for $\mathrm{Ca}(\mathrm{OH})_{2}$ pastes to release the $\mathrm{OH}$ - ions, so an additional time period of 5 days was also taken.

The microorganism used in the study was Candida albicans (ATCC 10231) since it is the most commonly encountered fungus in the root canals, $21 \%$ in primary infections [39] and $18 \%$ in cases of retreatments [40]. Dimorphic switching is observed in this species, which is a pivotal factor for biofilm formation and the pathogenic potential of $C$. albicans. There is an initial period of adherence $(0-2 \mathrm{~h})$ followed by microcolony formation (2-4 h). Dimorphic switching occurs thereafter with a transition from budding-yeast forms to filamentous pseudo- and true hyphal forms (4-6 h). The complexity of the biofilm increases with time, taking on three dimensional architecture with spatial heterogeneity as it matures ( $8-48 \mathrm{~h}$ ) [25], which is why the $48 \mathrm{~h}$ biofilm model was used. Sen et al. [41] investigated the growth patterns of C.albicans in relation to human radicular dentin and observed blastospores and hyphal structures on the root canal walls of all specimens. Dentin colonization may be an important step during infection of the root canal system. The invasion of dentinal tubules can protect microbial cells from the effects of intracanal procedures and may play an important role in the establishment of persistent root canal infections. Yeasts are on average 1 to $6 \mu \mathrm{m}$ in diameter, whereas hyphae are usually 1.9 to $2.6 \mu \mathrm{m}$ in diameter [42]. It has also been proposed that the contact-sensing (thigmotropism) ability of hyphal structures of Candida makes dentinal invasion inevitable. Therefore, on the basis of this invasive affinity to dentin, C.albicans is considered a dentinophilic microorganism [43]. Thus, the means to eradicate C.albicans from root canals becomes important for complete disinfection and to avoid reinfection.

Intracanal medicament possessing antimicrobial properties between appointments may reduce or eliminate microbes in the root canal system, thereby increasing the predictability and success of root canal treatment [43]. In our study, 2\% CHX has shown the $99.2 \%$ microbial inhibition at depths of 200 and $400 \mu \mathrm{m}$ from day 1 to 5 , which is not in accordance with the other studies in which $100 \%$ inhibition has been shown. 
Table 1. Mean \& Standard deviation of colony counts for different intracanal medicaments at 200 and $400 \mu \mathrm{m}$ depths at different time intervals.

\begin{tabular}{|c|c|c|c|c|c|c|c|c|c|c|c|c|}
\hline \multirow[b]{2}{*}{ Group } & \multicolumn{4}{|c|}{ Day 1} & \multicolumn{4}{|c|}{ Day 3} & \multicolumn{4}{|c|}{ Day 5} \\
\hline & \multicolumn{2}{|c|}{$200 \mu \mathrm{m}$} & \multicolumn{2}{|c|}{$400 \mu \mathrm{m}$} & \multicolumn{2}{|c|}{$200 \mu \mathrm{m}$} & \multicolumn{2}{|c|}{$400 \mu \mathrm{m}$} & \multicolumn{2}{|c|}{$200 \mu \mathrm{m}$} & \multicolumn{2}{|c|}{$400 \mu \mathrm{m}$} \\
\hline Propolis & 0.20 & 0.42 & 0.40 & 0.52 & 0.50 & 0.53 & 0.60 & 0.52 & 3.50 & 0.71 & 4.40 & 0.52 \\
\hline Neem (Alcoholic extract) & 1.60 & 0.52 & 3.20 & 0.42 & 5.50 & 0.53 & 9.40 & 0.52 & 12.60 & 0.52 & 17.40 & 0.52 \\
\hline $2 \%$ Chlorhexidine & 0.00 & 0.00 & 0.00 & 0.00 & 0.30 & 0.48 & 0.50 & 0.53 & 1.40 & 0.52 & 2.50 & 0.53 \\
\hline Calcium hydroxide & 28.40 & 0.52 & 42.80 & 0.42 & 55.50 & 0.53 & 69.40 & 0.52 & 82.60 & 0.52 & 87.40 & 0.52 \\
\hline Ethanol & 68.40 & 0.52 & 72.80 & 0.42 & 95.50 & 0.53 & 109.40 & 0.52 & 122.60 & 0.52 & 137.40 & 0.52 \\
\hline
\end{tabular}

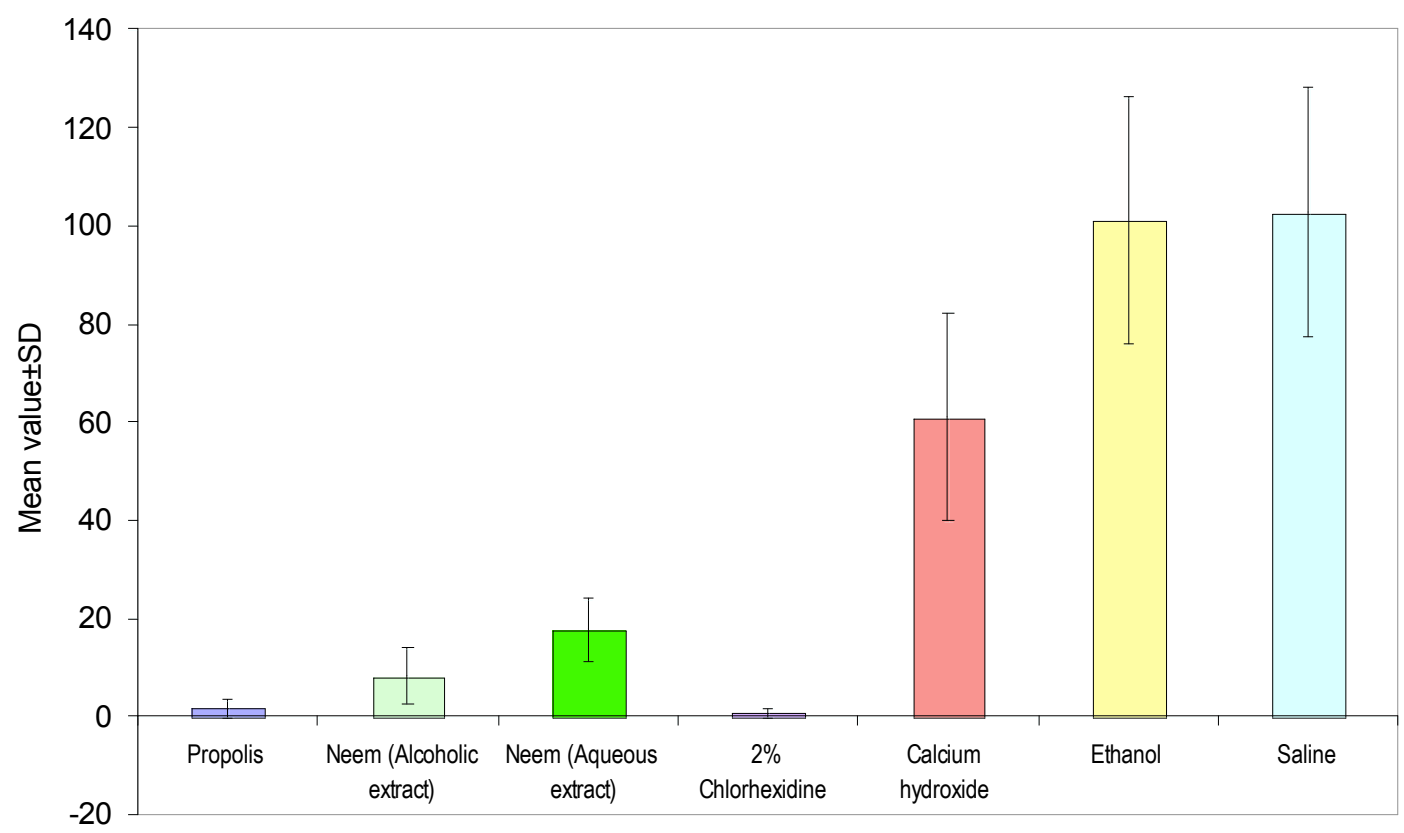

$2 \%$ Chlorhexidine $\simeq$ Propolis $\simeq$ Neem extract (Alc.) $>$ Neem $($ Aq. $)>$ Calcium hydroxide $>$ Ethanol $\simeq$ Saline

Fig. (3). Graph indicating the antimicrobial efficacy of different groups.

The possible reasons for this variance might be dentine, dentine components (hydroxyapatite \& collagen), heat-killed microbial cells and inflammatory exudates in the root canal system, which are inhibitors of CHX [44]. Yet, it has given maximum inhibition in our study. The explanation for this might be its high microbicidal dosage of $2 \%$ and increased diffusion of the medicament into the dentinal tubules [45]. Since, it is a positively charged hydrophobic and lipophilic molecule, it interacts with negatively charged phospholipids and lipopolysaccharides on the cell membrane of fungus and enters the cell through some type of active or passive transport mechanism, which alters the osmotic equilibrium of the cells. This increases the permeability of the cell wall, allowing the CHX molecule to penetrate into the micro-organism, followed by leakage of intracellular constituents, particularly phosphate entities such as adenosine triphosphate and nu- cleic acids. As a consequence, the cytoplasm becomes congealed, with resultant reduction in leakage; thus, there is a biphasic effect on membrane permeability [15]. It also binds to hydroxyapatite and soft tissues, changing their electrical field to compete with microbial binding, thus decreasing microbial adherence. The result of the present study was similar to that of Krithikadatta et al. [30], Gomes et al., [46] and Siqueria and Uzeda, [47] and Bhardwaj et al. [45] Basrani et al. [33] showed that $2 \%$ chlorhexidine gel produced a better antimicrobial action as compared to $0.2 \%$ chlorhexidine gel or calcium hydroxide mixed with $0.2 \%$ chlorhexidine.

In our study, Propolis showed 98.5\% microbial inhibition irrespective of depth and time, with no significant difference in comparison to the chlorhexidine group. Propolis exhibits 
antimicrobial, anti-inflammatory, healing, anesthetic and cariostatic properties [48]. Some components present in propolis extract, like flavonoids (quercetin, galangin, pinocembrin), caffeic acid, benzoic acid and cinnamic acid, probably act on the microbial membrane or cell wall site, causing functional and structural damages [25]. Takaisi- Kikuni and Schilcher [49] have reported that it prevents fungal cell division and also breaks down fungal cell wall and cytoplasm similar to the action of some antibiotics. Kujumgiev et al. [50] have reported that the antimicrobial action of propolis can be due to flavonoids and esters of phenolic acids. Koo et al. [51] tested the antimicrobial activity of propolis using the agar diffusion method and observed that the propolis extract significantly inhibited all of the microorganisms tested, including facultative and strict anaerobic species. Oncag et al. [52] observed that propolis had good in vitro antimicrobial activity against $E$. faecalis in the root canals of extracted teeth, suggesting that it could be used as an alternative intracanal medicament.

Azadirachta indica (Neem) has also been used in the study. There has been no study so far of dentinal tubule disinfection with Azadirachta indica (AI), this probably is the first study of its kind. The presence of active constituents such as nimbidin, nimbin, nimbolide, gedunin, azadirachtin, mahmoodin, margolone, and cyclictrisulphide contributes to the antifungal activity of AI [53]. These active constituents uncouple mitochondrial oxidative phosphorylation; thus, inhibiting the respiratory chain [54]. This resulted in its antiadherence activity by altering the microbial adhesion and the ability of the microorganism to colonize thereby causing maximum reduction in adherence to dentin. Rajashekharan et al. [55] have proposed that the inhibitory activities of the leaf extracts of AI were both organism and solvent dependent. Thus, to evaluate the effect of solvent on Candida albicans, both aqueous and alcoholic extracts were taken. Nayak et al. [29] conducted a study in which the minimum inhibitory concentration of aqueous extract of $\mathrm{AI}$ was $7.5 \%$ as compared to the alcoholic extract of AI which was $3.75 \%$, thus showing alcoholic extract to be better and more efficacious, which is in support of our study.

Calcium hydroxide, the gold standard of intracanal medicament was also taken as a test group. Literature indicates that Candida species are resistant to calcium hydroxide, [26] which has been again verified in our study. Waltimo et al. [56] evaluated the susceptibility of 7 strains of C. albicans to 4 disinfectants: iodine potassium iodide, chlorhexidine acetate, sodium hypochlorite, and calcium hydroxide. C. albicans cells were highly resistant to calcium hydroxide. It survives in a wide range of $\mathrm{pH}$ values, the alkalinity of saturated calcium hydroxide solution may not have any effect on $C$. albicans. The alkalinity of calcium hydroxide also reduces due to the buffering capacity of dentin. In addition, calcium hydroxide solution may readily display the $\mathrm{Ca}++$ ions necessary for the growth and morphogenesis of Candida. These mechanisms may explain why calcium hydroxide has been found to be ineffective against C. albicans [57].

Ethanol was also taken as a test group to check if it influenced the activity of propolis or AI. Ethanol showed slight inhibition of microorganism but there was no significant difference between ethanol and saline, which was taken as a negative control. Previously, a study conducted by Ferreira et al., [14] had concluded that Ethanol did not influence the antimicrobial effect of ethanolic extract of propolis.

\section{CONCLUSION}

Under the limitations of the study, it can be concluded that Propolis and alcoholic extract of Azadirachta indica performed equally well as that of $2 \%$ Chlorhexidine and thus can be probable alternatives to chlorhexidine, but further in vivo and long term studies are warranted.

\section{CONFLICT OF INTEREST}

The authors confirm that this article content has no conflict of interest.

\section{ACKNOWLEDGEMENTS}

Declared none.

\section{REFERENCES}

[1] Love RM, Jenkinson HF. Invasion of dentinal tubules by oral bacteria. Crit Rev Oral Biol Med 2002; 13: 171-83.

[2] Sirén EK, Haapasalo MPP, Ranta K, Salmi P, Kerosuo ENJ. Microbiological findings and clinical procedures in endodontic cases selected for microbiological investigation. Int Endod J 1997; 30: 91-5.

[3] Wu MK, Dummer PM, Wesselink PR. Consequences of and strategies to deal with residual post-treatment root canal infection. Int Endod J 2006; 39: 343-56.

[4] Siqueira JF Jr, Sen BH. Fungi in endodontic infections. Oral Surg Oral Med Oral Pathol Oral Radiol Endod 2004; 97: 632-41.

[5] Calderone RA, Fonzi WA. Virulence factors of Candida albicans. Trends Microbiol 2001; 9: 327-35.

[6] Hagihara Y, Kaminishi H, Cho T, Tanaka M, Kaita H. Degradation of human dentine collagen by an enzyme produced by the yeast Candida albicans. Arch Oral Biol 1988; 33: 617-9.

[7] San-Blas G, Travassos LR, Fries BC, et al. Fungal morphogenesis and virulence. Med Mycol 2000; 38(suppl 1): 79-86.

[8] Phan QT, Belanger PH, Filler SG. Role of hyphal formation in interactions of Candida albicans with endothelial cells. Infect Immun 2000; 68: 3485-90.

[9] Cotter G, Kavanagh K. Adherence mechanisms of Candida albicans. Br J Biomed Sci 2000; 57: 241-9.

[10] Marsh P, Martin MV. Oral microbiology. 4th ed. Oxford: England, Wright 1999.

[11] Calderone R, Suzuki S, Cannon R, et al. Candida albicans: adherence, signaling and virulence. Med Mycol 2000; 38(suppl 1): 12537.

[12] Lindskog S, Pierce AM, Blomlöf L. Chlorhexidine as a root canal medicament for treating inflammatory lesions in the periodontal space. Endod Dent Traumatol 1998; 14: 186-90.

[13] Gelinas P, Goulet J. Neutralization of the activity of eight disinfectants by organic matter. J Appl Bacteriol 1983; 54: 243-7.

[14] Ferreira FB, Torres SA, Rosa OP, et al. Antimicrobial effect of propolis and other substances against selected endodontic pathogens. Oral Surg Oral Med Oral Pathol Oral Radiol Endod 2007; 104: 709-16.

[15] Kandaswamy D, Venkateshbabu N, Gogulnath D, Kindo AJ. Dentinal tubule disinfection with $2 \%$ chlorhexidine gel, propolis, morinda citrifolia juice, $2 \%$ povidone iodine and calcium hydroxide. Int Endod J 2010; 43: 419-23.

[16] Kausik B, Chattopadhyey I, Benerjee RK, Bandyopdyey U. Biological activities and medicinal properties of neem. Curr Sci 2002; 82: $1336-44$

[17] Tronstad L, Andreassen JO, Haselgreen G, Kristerson L, Riis I. pH changes in dental tissues after root canal filling with calcium hydroxide. J Endod 1981; 7: 17-21.

[18] Torneck CD, Moe H, Howley TP. The effect of $\mathrm{Ca}(\mathrm{OH})_{2}$ solution on porcine pulp fibroblasts in vitro. J Endod 1983; 9: 131-6. 
[19] Safavi KE, Dowden WE, Introcaso JH, Langeland K. A comparison of antimicrobial effects of calcium hydroxide and iodinepotassiumiodide. J Endod 1985; 11: 454-6.

[20] Hasselgren G, Olsson B, Cvek M. Effects of calcium hydroxide and sodium hypochlorite on the dissolution of necrotic porcine muscle tissue. J Endod 1988; 14: 125-7.

[21] Beltes PG, Pissiotis E, Koulaouzidou E, Kortsaris AH. In vivo evaluation of chlorhexidine solution and sodium hypochlorite solution as root canal irrigants. J Endod 1997; 8: 200-4.

[22] Safavi KE, Nichols FC. Alteration of biological properties of bacterial lipopolysaccharide by $\mathrm{Ca}(\mathrm{OH})_{2}$ treatment. J Endod 1994; 20: $127-9$.

[23] Haapasalo M, Ørstavik D. In vitro infection and disinfection of dentinal tubules. J Dent Res 1987; 66: 1375-9.

[24] Kandaswamy D, Venkateshbabu N, Gogulnath D, Kindo AJ. Dentinal tubule disinfection with $2 \%$ chlorhexidine gel, propolis, morinda citrifolia juice, $2 \%$ povidone iodine, and calcium hydroxide. Int Endod J 2010; 43: 419-23.

[25] Tyagi SP, Sinha DJ, Garg P, Singh UP, Mishra CC, Nagpal R. Comparison of antimicrobial efficacy of propolis, Morinda citrifolia, Azadirachta indica (Neem) and 5\% sodium hypochlorite on Candida albicans biofilm formed on tooth substrate: An in-vitro study. J Conserv Dent 2013; 16: 532-5.

[26] Vaghela DJ, Kandaswamy D, Venkateshbabu N, Jamini N, Arathi G. Disinfection of dentinal tubules with two different formulations of calcium hydroxide as compared to $2 \%$ chlorhexidine: As intracanal medicaments against Enterococcus faecalis and Candida albicans: An in vitro study. J Conserv Dent 2011; 14: 182-6.

[27] Shingare P, Chaugule V. Comparative evaluation of antimicrobial activity of miswak, propolis, sodium hypochlorite and saline as root canal irrigants by microbial culturing and quantification in chronically exposed primary teeth. Germs $2011 ; 1: 12-21$

[28] Dubey S, Chaodary M, Gupta P. Comparative study of the antimicrobial efficiency of neem leaf extract, sodium hypochlorite and biopure MTAD: An in vitro study. Ind J Dent Adv 2012; 4: 740-3.

[29] Nayak A, Nayak RN, Somya GB, Kishore B, Mithun K. Evaluation of antibacterial and anticandidial efficacy of aqueous and alcoholic extract of Neem (Azadirachta indica) an in vitro study. IJRAP $2011 ; 2: 230-5$

[30] Krithikadatta J, Indira R, Dorothykalyani AL. Disinfection of dentinal tubules with $2 \%$ chlorhexidine, $2 \%$ metronidazole, bioactive glass when compared with calcium hydroxide as intracanal medicaments. J Endod 2007; 33: 1473-6,

[31] Simon ST, Bhat KS, Roy F. Effect of four vehicles on the pH of calcium hydroxide and the release of calcium ion. Oral Surg Oral Med Oral Pathol Oral Radiol Endod 1995; 80: 459-64.

[32] Fernandez-Vigo J, Refojo MF, Verstraeten T. Evaluation of a viscoelastic solution of hydroxypropyl methylcellulose as a potential vitreous substitute. Retina 1990; 10: 148-52.

[33] Basrani B, Tjäderhane L, Santos JM, et al. Efficacy of chlorhexidine- and calcium hydroxide- containing medicaments against Enterococcus faecalis in vitro study. Oral Surg Oral Med Oral Pathol Radiol Endod 2003; 96: 618-24.

[34] Lynne RE, Lieweher FR, West LA, Patton WR, Buxton TB, McPherson JC. In vitro antimicrobial activity of various medication preparations on E. faecalis in root canal dentin. J Endod 2003; 29: $187-90$.

[35] Love RM. Regional variation in root dentinal tubule infection by Streptococcus gordonii. J Endod 1996; 22: 290-3.

[36] Lin S, Tsesis I, Zukerman O, Weiss EI, Fuss Z. Effect of electrophoretically activated calcium hydroxide on bacterial viability in dentinal tubules: in vitro. Dent Traumatol 2005; 21(1): 42-5.

[37] Neelakantan P, Sanjeev K, Subbarao CV. Duration-dependent susceptibility of endodontic pathogens to calcium hydroxide and chlorhexidine gel used as intracanal medicament: An in vitro evaluation. Oral Surg Oral Med Oral Pathol Oral Radiol Endod 2007; 104: e138-41.

[38] Beltes GP, Pissiotis E, Koulaouzidou E, Kortsaris AH. In vitro release of hydroxyl ions from six types of calcium hydroxide nonsetting pastes. J Endod 1997; 23: 413-5.

[39] Baumgartner JC, Watts CM, Xia T. Occurrence of Candida albicans in infections of endodontic origin. J Endod 2000; 26: 695-8.

[40] Siqueira JF Jr., Rôças IN. Diversity of endodontic microbiota revisited. J Dent Res 2009; 88: 969-81.

[41] Sen BH, Safavi KE, Spangberg LS. Growth patterns of Candida albicans in relation to radicular dentin. Oral Surg Oral Med Oral Pathol Oral Radiol Endod 1997; 84: 68-73.

[42] Waltimo TM, Sire'n EK, Torkko HL, Olsen I, Haapasalo MP. Fungi in therapy-resistant apical periodontitis. Int Endod J 1997; 30: $96-101$

[43] Ørstavik D, Haapasalo M. Disinfection by endodontic irrigants and dressings of experimentally infected dentinal tubules. Endod Dent Traumatol 1990; 6: 142-9.

[44] Mohammadi Z, Abbott PV. The properties and applications of chlorhexidine in endodontics. Int Endod J 2009; 42: 288-302.

[45] Bhardwaj A, Ballal S, Velmurugan N. Comparative evaluation of the antimicrobial activity of natural extracts of Morinda citrifolia, papain and aloe vera (all in gel formulation), $2 \%$ chlorhexidine gel and calcium hydroxide, against Enterococcus faecalis: An in vitro study. J Conserv Dent 2012; 15: 293-7.

[46] Gomes BP, Souza SF, Ferraz CC, et al. Effectiveness of $2 \%$ chlorhexidine gel and calcium hydroxide against Enterococcus faecalis in bovine root dentin in vitro. Int Endod J 2003; 36: 267-75.

[47] Siqueira JF Jr, Uzeda M. Intracanal medicaments: Evaluation of the antibacterial effects of chlorhexidine, metronidazole, and calcium hydroxide associated with three vehicles. J Endod 1997; 23: 167-9.

[48] Garg P, Tyagi SP, Sinha DJ, Singh UP, Malik V, Maccune ER. Comparison of antimicrobial efficacy of propolis, Morinda citrifolia, Azadirachta indica, triphala, green tea polyphenols and 5.25\% sodium hypochlorite against Enterococcus faecalis biofilm. Saudi Endod J 2014; 4: 122-7.

[49] Takaisi-Kikuni NB, Schilcher H. Electron microscopic and microcalorimetric investigations of the possible mechanism of the antibacterial action of a defined propolis provenance. Planta Med 1994; 60: 222-7.

[50] Kujumgiev A, Tsvetkova I, Serkedjieva Y, Bankova V, Christov R, Popov S. Antibacterial, antifungal and antiviral activity of propolis of different geographic origin. J Ethnopharmacol 1999; 64: 235-40.

[51] Koo H, Gomes BP, Rosalen PL, Ambrosano GM, Park YK, Cury JA. In vitro antimicrobial activity of propolis and Arnica montana against oral pathogens. Arch Oral Biol 2000; 45: 141-8.

[52] Oncag O, Cogulu D, Uzel A, Sorkun K. Efficacy of propolis as an intracanal medicament against Enterococcus faecalis. Gen Dent 2006; 54: 319-22.

[53] Ghosh A, Chakrabarti, Roy P, Bhadury S, Nag T, Sarkar S. Bioremidation of heavy metals from neem leaf extract by chelation with dithizone. Asian Pharm Clin Res 2009; 2: 87-92

[54] Biswas K, Chattopadhyay I, Banerjee RK, Bandyopadhyay U. Biological activities and medicinal properties of neem (Azadirachta indica). Curr Sci 2002; 82: 1336-45.

[55] Rajasekaran C, Meignanam E. Vijayakumar V, et al. Investigations on antibacterial activity of leaf extracts of Azadirachta indica A.Juss (Meliaceae): A traditional medicinal plant of India. Ethnobotanical Leaflets 2008; 12: 1213-7.

[56] Waltimo TM, Ørstavik D, Sire'n EK, Haapasalo MP. In vitro susceptibility of Candida albicans to four disinfectants and their combinations. Int Endod J 1999; 32: 421-9

[57] Sen BH, Akdeniz BG, Denizci AA. The effect of ethylenediaminetetraacetic acid on Candida albicans. Oral Surg Oral Med Oral Pathol Oral Radiol Endod 2000; 90: 651-5. 